\title{
PENDAMPINGAN BELAJAR MATEMATIKA DENGAN METODE "GASING" KEPADA MURID SEKOLAH DASAR NEGERI 008 BELAKANG PADANG
}

\section{MATHEMATICS LEARNING ASSISTANCE WITH THE "GASING" METHOD TO ELEMENTARY SCHOOL STUDENTS 008 BELAKANG PADANG}

\author{
Asmaul Husna ${ }^{1}$, Riska Novia sari ${ }^{2}$ \\ ${ }^{1,2}$ (Program Studi pendidikan Matematika, Fakultas Keguruan dan Ilmu Pendidikan, Universitas Riau \\ Kepulauan, Batam) \\ Iasmaul_uul25@yahoo.com, ${ }^{2}$ riskanovia30@gmail.com
}

\begin{abstract}
Abstrak
Pelaksanaan program pengabdian ini didasarkan kepada murid Sekolah Dasar (SD) Negeri 008 Belakang Padang yang merasa banyak menemui kesulitan dalam pembelajaran matematika. Hal ini disebabkan karena pembelajaran yang dilaksanakan selama ini disekolah karena keterbatasan jumlah guru, guru hanya mengejar bagaimana materi selesai disampaikan kepada murid sehingga sangat jarang menggunakan metode-metode pembelajaran yang inovatif. Terbukti dengan kurangnya kemampuan murid dalam operasi dasar Aritmatika (perkalian, pembagian, penjumlahan dan pengurangan). Tujuan pelaksanaan program ini adalah : (a) meningkatkan pemahaman dan keterampilan murid dalam operasi dasar aritmatika, (b) melatih dan mendampingi murid dengan menggunakan metode pembelajaran "GASING". Metode pelaksanaan kegiatan meliputi tiga tahap, yaitu : perencanaan, tindakan dan evaluasi. Hasil pelaksanaan program adalah adanya peningkatan pengetahuan dan keterampilan murid pada operasi dasar aritmatika dalam kategori baik.
\end{abstract}

Kata Kunci : Metode Pembelajaran, Gasing

\section{Abstract}

The implementation of this service program was based on students from the Belakang Padang 008 State Elementary School (SD) who felt that many had difficulties in learning mathematics. This is because learning has been carried out so far in schools because of the limited number of teachers, teachers only pursue how the material is delivered to students so that it is very rare to use innovative learning methods. Evidenced by the lack of students' abilities in basic Arithmetic operations (multiplication, division, addition and subtraction). The objectives of the program are: (a) to increase students' understanding and skills in basic arithmetic operations, (b) to train and assist students by using the "GASING" learning method. The method of implementing the activity includes three stages, namely: planning, action and evaluation. The results of the program implementation are an increase in students' knowledge and skills in basic arithmetic operations in good categories.

Keywords: Learning Method, GASING

\section{PENDAHULUAN}

Masalah pendidikan di Pulau Sarang semua anak belum bisa menikmati pendidikan seperti yang seharusnya mulai dari jenjang TK sampai Perguruan Tinggi, kekurangannya di Pulau Sarang hanya ada Sekolah Dasar saja untuk Taman Kanak-kanak 
(TK), Sekolah Menengah Pertama (SMP) dan Sekolah Menengah Atas (SMA) belum ada. Untuk anak-anak yang ingin melanjutkan ke tingkat SMP dan SMA harus pergi ke daerah Belakang Padang. Jumlah guru di Sekolah Dasar pulau sarang juga tidak sebanding dengan rasio jumlah murid disana. hal ini dikarenakan keterbatasan sumber daya manusia yang ada disana. Berdasarkan hasil wawancara dengan beberapa murid usia sekolah dan beberapa orang tua murid di RT.01 dan RT.02, diperoleh informasi bahwa, ketika murid menjumpai permasalahan dalam materi pembelajaran disekolah mereka merasa kesulitan ingin berdiskusi dengan siapa untuk menyelesaikan permasalahannya hal ini dikarenakan murid-murid Sekolah Dasar disana tidak mengenyam pendidikan di Taman Kanak-kanak (TK) diperparah lagi banyak orang tua murid di pulau sarang yang buta aksara.

Informasi yang cukup menarik dari beberapa murid Sekolah Dasar (SD) di RT.01 dan RT.02 Pulau Sarang untuk pembelajaran matematika khususnya pada masalah aritmatika dasar yaitu kabataku (kali, bagi, tambah dan kurang) murid sering mengalami kesulitan disaat menyelesaikan tugas yang diberikan oleh sekolah yang berhubungan dengan masalah tersebut karena murid merasa kesulitan untuk mengingat jumlah khusunya dalam perkalian yang dalam artian banyak murid Sekolah Dasar yang tidak hafal perkalian dasar 1 sampai 10. Hal ini disebabkan karena pembelajaran yang dilaksanakan selama ini disekolah karena keterbatasan jumlah guru, guru hanya mengejar bagaimana materi selesai disampaikan kepada murid sehingga sangat jarang menggunakan metode-metode pembelajaran yang inovatif. Murid belajar matematika lebih banyak melalui penjelasan secara langsung oleh guru yang didominasi dengan pemberian ceramah. Hal ini terjadi sebagai akibat dari pemahaman serta keterampilan guru untuk menggunakan metode-metode inovatif dalam pembelajaran matematika juga kurang. Sebagai akibatnya murid belajar matematika dengan cara-cara yang kurang bermakna. Murid cenderung menghafal konsep atau prosedur matematis tertentu. Sehingga mengakibatkan murid cepat lupa dengan konsep-konsep yang mereka hafal.

Secara umum, proses pembelajaran disekolah berlangsung dengan cukup baik, dengan penggunaan media dan metode pengajaran yang belum optimal. Dan sangat diperlukan variasi media dan metode pembelajaran, sehingga proses belajar mengajar dapat meningkat mutunya. Untuk membantu meningkatkan mutu proses belajar mengajar, khususnya dalam bidang matematika, antara lain dengan memberikan variasi media dan 
metode pembelajaran. Sehingga minat belajar murid dapat ditingkatkan, terutama dalam mata pelajaran Matematika yang sering dianggap sulit. Kesan ini dapat dikurangi dengan memberikan variasi media dan model pembelajaran yang dapat menarik minat murid.

Keberhasilan proses belajar mengajar sangat ditentukan oleh metode pengajaran yang baik, media pembelajaran yang mendukung serta suasana proses belajar yang kondusif (Husna, 2017:20). Keterampilan pendidik dalam menumbuhkan motivasi peserta didik juga merupakan salah satu faktor yang mempengaruhi keberhasilan tersebut.

Menurut Ghazali : "Agar peserta didik mudah mengingat, menceritakan dan melaksanakan sesuatu (pelajaran) yang pernah diamati (diterima, dialami) di kelas, perlu didukung dengan peragaan-peragaan (media pengajaran) yang konkret.” Stimulus dari luar termasuk bahan pengajaran meninggalkan kesan /tanggapan yang tahan lama dalam ingatan dan mudah direproduksi jika masuk ke dalam jiwa melalui indranya. (Rohani,2002).

Penggunaan media pendidikan secara tepat dapat mengatasi sikap pasif peserta didik. Secara rinci media pendidikan berguna untuk :

1. Menimbulkan kegairahan belajar.

2. Memungkinkan interaksi yang lebih langsung antara peserta didik dengan lingkungan dan kenyataan.

3. Memungkinkan peserta didik belajar menurut kemampuan dan minatnya.(Arief,2000).

Keterampilan untuk mengadakan variasi juga sangat berpengaruh pada keberhasilan belajar peserta didik.

Beberapa manfaat memberikan variasi adalah :

1. Menimbulkan dan meningkatkan perhatian peserta didik terhadap proses belajar mengajar.

2. Meningkatkan motivasi dan rasa ingin tahu.

3. Membentuk sikap yang positif.

4. Tercipta suasana nyaman dalam belajar dan terhindar dari kebosanan.(Hendyat,2003).

Mempertimbangkan jumlah murid usia sekolah Dasar di RT.01 dan RT.02 Pulau Sarang yang cukup banyak, dengan pemahaman yang masih kurang dalam pembelajaran 
matematika, khususnya dalam menggunakan metode-metode yang inovatif dalam pembelajaran matematika, maka Dosen bersama dengan dengan mahasiswa sebagai tim pelaksana memandang perlu untuk mengadakan kegiatan pembelajaran tambahan yang menggunakan metode yang inovatif dengan melibatkan para murid usia sekolah dasar (SD) di daerah ini, hal ini dikarenakan murid-murid didaerah ini membutuhkan penyegaran terkait metode pembelajaran yang selama ini cenderung dituntun untuk menghafal. Agar dapat meningkatkan minat mereka dalam pembelajaran khususnya dalam pembelajaran matematika.

Adapun metode pembelajaran yang inovatif yang tim pelaksana berikan pada murid sekolah dasar di RT.01 dan RT.02 Pulau Sarang adalah metode GASING (gampang, asyik dan menyenangkan) yang diciptakan oleh Prof. Yohanes Surya. Matematika GASING (Gampang Asyik Menyenangkan) adalah suatu cara belajar matematika yang dilakukan secara langkah demi langkah untuk memperoleh suatu capaian atau hasil. Selama proses pembelajaran, murid dikenalkan dengan benda-benda konkret diarahkan ke simbol-simbol abstrak, dan kemudian mencongak sebagai bentuk dari evaluasi. (Shanty dan Wijaya, 2012; Prahmana, 2013; Kolnel,et al, 2015) mendeskripsikan matematika GASING sebagai proses pembelajaran yang membuat murid belajar secara easy, fun and enjoyable. Gampang (easy) dapat diartikan ketika murid belajar, murid dikenalkan dengan logika matematika yang mudah dipelajari dan diingat, asyik (fun) berarti selama proses pembelajaran murid mempunyai keinginan untuk belajar tanpa adanya paksaan, menyenangkan dapat diartikan adanya kepuasan dalam proses belajar karena penggunaan alat peraga dan permainan.

Metode GASING adalah metode pembelajaran alternatif untuk mengajarkan materi matematika untuk murid-murid sekolah dasar. Diharapkan dengan metode ini, muridmurid menyukai pelajaran tentang operasi dasar aritmatika khususnya perkalian, dengan cara belajar sambil bermain. Sosialisasi metode ini diperlukan untuk memberikan metode alternatif bagi murid-murid sekolah dasar, sehingga pelajaran matematika dapat diajarkan dengan cara yang lebih menarik dan menyenangkan. Sehingga dapat meningkatkan hasil belajar murid menjadi lebih baik.

Metode GASING ini Menurut Prof.Yohanes Surya (Dalam Shanty dan Wijaya, 2012), ketika belajar suatu materi, ada titik kritis yang harus dilewati. Titik kritis yang 
dimaksud adalah titik kritis GASING. Setelah melalui titik kritis dengan baik, murid tidak akan mengalami kesulitan lagi untuk mengerjakan soal dari materi yang diberikan tersebut.

\section{METODOLOGI}

\section{Bentuk Kegiatan}

Berdasarkan permasalahan yang dihadapi seperti terungkap dalam bagian sebelumnya, solusi yang ditawarkan yaitu dengan Mengadakan pendampingan kepada murid Sekolah Dasar (SD) di RT.01 dan RT.02 Pulau Sarang untuk menambah pengetahuan para murid tentang penggunaan metode pembelajaran yang inovatif seperti penggunaan metode GASING untuk menanamkan konsep cara mudah memahami operasi dasar Aritmatika(perkalian, pembagian, penjumlahan dan pengurangan) dalam pembelajaran dan menumbuhkan minat mereka terhadap pembelajaran matematika.

\section{Teknis Pelaksanaan}

Pelaksanaan kegiatan terdiri atas tiga langkah utama, yaitu : perencanaan, tindakan dan evaluasi.

a. Perencanaan

Pada kegiatan perencanaan tim pelaksana mengundang mitra untuk dijelaskan maksud, tujuan dan teknis pelaksanaan kegiatan pelatihan, sosialisasi program pada mitra, dan penyusunan program pelatihan.

b. Tindakan

Tindakan dalam kegiatan ini berupa implementasi program. Kegiatan-kegiatan yang dilakukan adalah (a) meningkatkan pengetahuan dan keterampilan murid dalam pembelajaran matematika dengan penggunaan metode GASING pada operasi dasar aritmatika, (b) mendampingi murid dalam pembelajaran matematika dengan metode GASING.

c. Evaluasi

Evaluasi dalam kegiatan ini diperlukan untuk mengetahui sejauh mana pemberian metode yang dilakukan tim pelaksana dipahami dan bisa membantu permasalahan murid. Contoh untuk penggunaan metode GASING tim mengevaluasi dengan cara memberikan beberapa soal yang berhubungan dengan dasar aritmatika dan diminta 
diselesaikan secara langsung, disana akan terlihat sejauh mana metode ini akan membantu murid dalam meningkatkan hasil belajarnya.

\section{Waktu Pelaksanaan}

Kegiatan pendampingan pembelajaran dengan metode GASING dilaksanakan delapan kali pertemuan, yaitu pada hari senin tanggal 23 Juli 2018 sampai 30 Juli 2018.

\section{Keterlibatan Anggota}

Anggota disini berperan sebagai pemateri dalam pengenalan metode serta mencontohkan secara langsung penggunaannya kepada murid-murid sekolah Dasar di RT.01 dan RT.02 RW.06.

\section{PEMBAHASAN}

Adapun garis besar hasil pelaksanaan kegiatan adalah sebagai berikut:

1. Langkah awal kegiatan, yaitu penyampaian gagasan pelaksanaan pengabdian kepada Ketua RW.06 Pulau Sarang berjalan lancar. Murid-murid Usia Sekolah Dasar (SD) di lokasi pengabdian siap menerima kedatangan tim Pelaksana.

2. Hasil pelaksanaan kegiatan pelatihan

a. Kegiatan pelatihan penggunaan metode GASING dilaksanakan pada tanggal 23 dan 30 Juli 2018. Kegiatan pengabdian dihadiri oleh 13 orang peserta dan peserta menunjukkan antusiasme cukup besar terhadap program pengabdian.

b. Materi pelatihan dapat semuanya disampaikan oleh tim pelaksana.

c. Peningkatan Kemampuan peserta pelatihan dalam penguasaan materi dalam kategori cukup baik.

3. Program pelatihan berhasil memberikan penyegaran kepada murid Sekolah Dasar (SD) dalam perhitungan dasar aritmatika.

4. Penyusunan laporan akhir hasil yang dilakukan secara tertulis kepada LPPM UNRIKA.

\section{Pembahasan Hasil Pelaksanaan Kegiatan}

Berdasarkan hasil kegiatan yang telah dipaparkan pada hasil, bahwa kegiatan pengabdian ini mendapat respon yang positif dari murid-murid Sekolah Dasar (SD) di RW.06 Kelurahan Sekanak Raya, dimana para peserta antusias mengikuti kegiatan, para murid mengikuti dengan penuh semangat sehingga ketika mereka disuruh untuk 
mengerjakan latihan yang diberikan para murid bisa menyelesaikannya dengan baik dan juga mereka dengan senang hati membantu dalam proses awal sampai akhir.
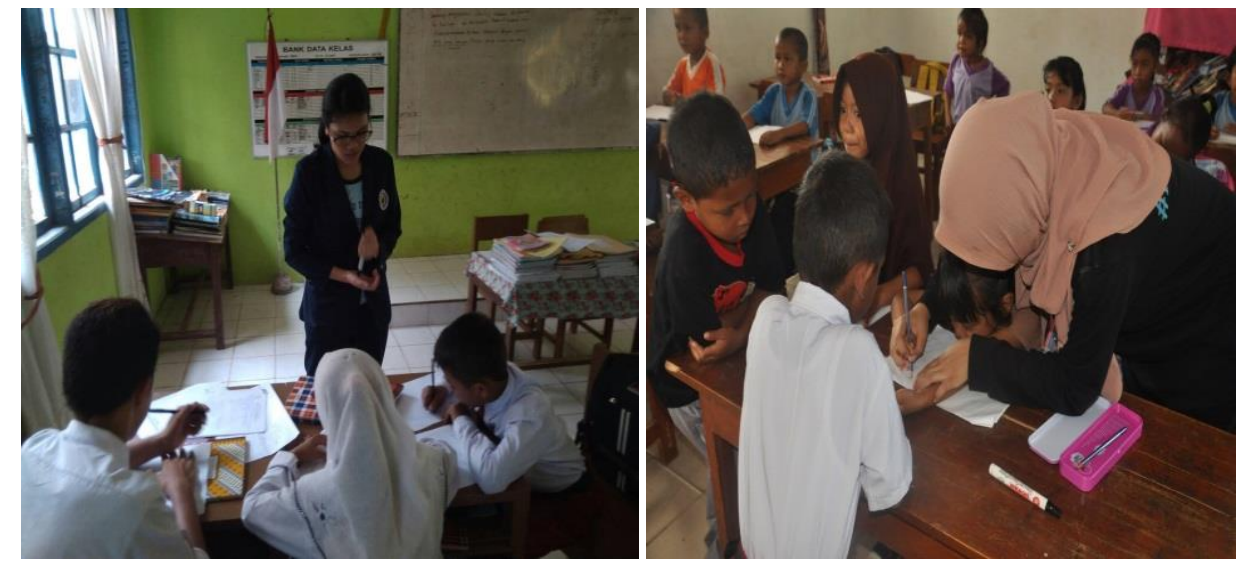

Figur 1. Foto Pelaksanaan pembelajaran dengan metode "GASING"

Disisi lain masih ditemukan beberapa kendala dalam pelaksanaan, misalnya dari segi komunikasi. Murid disana masih belum fasih berbahasa Indonesia baik dan benar, sehingga dalam pembelajaran mereka masih menggunakan bahasa daerah (bahasa melayu) dan ada sebagian kata-kata yang mereka ucapkan belum dipahami tim pelaksana.

\section{KESIMPULAN}

Berdasarkan uraian pada hasil dan pembahasan di atas, maka dapat disimpulkan sebagai berikut: Pelaksanaan kegiatan pelatihan penggunaan metode GASING untuk menanamkan konsep cara mudah menghitung aritmatika dasar berjalan dengan baik. Tanggapan mitra terhadap pelaksanaan kegiatan pelatihan cukup baik. Hal ini dapat dilihat dari indikator kehadiran murid, dan selama kegiatan berlangsung mereka sangat antusias mengikuti kegiatan dari awal sampai akhir kegitan.

\section{REFERENSI}

Arief. S., 2000, Media Pendidikan, Pengertian, Pengembangan dan Pemanfaatannya. Bandung: PT. Raja Grafindo Persada.

Rohani, A. 2002 , Pengelolaaan Pengajaran. Jakarta:Rineka Cipta.

Hendyat Soetopo, 2002, Pendidikan dan Pembelajaran : Teori, Masalah dan Praktek, UMM Press 
Husna, Asmaul. 2017. Pelatihan Penggunaan Metode Jarimatika Untuk Menanamkan Konsep Cara Mudah Menghitung Perkalian Pada Siswa Sekolah Dasar RW. 01 Kelurahan Kibing. Minda Baharu. 1(1). 19-24

Indarti.2008. Teknik Berhitung Dengan Menggunakan GASING Guna Mendukung Kecerdasan murid. Jakarta: Bina Sarana Informatika.

Kolnel, Rusli,P.D, et al. 2015. Pengaruh Pembelajaran Matematika Gasing Pada Materi Geometri Terhadap Hasil Belajar Siswa Kelas VII Sekolah Menengah Pertama. Jurnal Pendidikan Matematika STKIP Surya Tangerang. 2 (1). 70-76

Panduan Pengabdian Pada Masyarakat. 2018. Lembaga Penelitian dan Pengabdian pada Masyarakat (LPPM) Universitas Riau Kepulauan.

Parwati, Ni Nyoman dan Ariawan, I Putu Wisna. 2013. IbM Media Pembelajaran Matematika SD. Universitas Pendidikan Ganesha.

Prahmana, R.C.I. 2013. Designing Division Operation Learning in The Mathematics GASING. The First South Asia Design/Development Research 2013 International Conference, 391-398. Palembang: Sriwijaya University.

Shanty, N.O. \& Wijaya, S. 2012. Rectangular Array Model Supporting Students Spatial Structuring in Learning Multiplication. Journal on Mathematics Education (IndoMS-JME), 3 (2), 174-186

Zainul, A dan Nasution, N.2001. Penilaian Hasil Belajar, PAU-PPAI, Jakarta. 